\title{
OPTIMIZED MICROWAVE-ASSISTED EXTRACTION OF 6-GINGEROL FROM ZINGIBER OFFICINALE ROSCOEAND EVALUATION OF ANTIOXIDANT ACTIVITY IN VITRO*
}

\author{
Wei Liư ${ }^{1,2,3}$, Chun-Li Zhou ${ }^{1,2,3,4}$, Jing Zhao ${ }^{1,2,3}$, Dong Chen ${ }^{1,2,3}$, Quan-Hong Li $i^{1,2,3 凶}$ \\ ${ }^{1}$ College of Food Science and Nutritional Engineering, China Agricultural University \\ Beijing 100083, China \\ ${ }^{2}$ Key Laboratory of Fruit and Vegetable Processing, Ministry of Agriculture \\ Beijing 100083, China \\ ${ }^{3}$ Research Center for Fruit and Vegetable Processing Engineering, Ministry of Education \\ Beijing 100083, China \\ ${ }^{4}$ School of Life Science, Jiangxi Science and Technology Normal University \\ Nanchang 330013, China
}

\begin{abstract}
Background. 6-Gingerol is one of the most pharmacologically active and abundant components in ginger, which has a wide array of biochemical and pharmacologic activities. In recent years, the application of microwave-assisted extraction (MAE) for obtaining bioactive compounds from plant materials has shown tremendous research interest and potential. In this study, an efficient microwave-assisted extraction (MAE) technique was developed to extract 6-gingerol from ginger. The extraction efficiency of MAE was also compared with conventional extraction techniques.

Material and methods. Fresh gingers (Zingiber officinale Rosc.) were harvested at commercial maturity (originally from Shandong, laiwu, China). In single-factor experiments for the recovery of 6-gingerol, proper ranges of ratio of liquid to solid, ethanol proportion, microwave power, extraction time were determined. Based on the values obtained in single-factor experiments, a Box-Behnken design (BBD) was applied to determine the best combination of extraction variables on the yield of 6-gingerol.

Results. The optimum extraction conditions were as follows: microwave power $528 \mathrm{~W}$, ratio of liquid to solid $26 \mathrm{~mL} \cdot \mathrm{g}^{-1}$, extraction time $31 \mathrm{~s}$ and ethanol proportion $78 \%$. Furthermore, more 6-gingerol and total polyphenols contents were extracted by MAE than conventional methods including Maceration (MAC), Stirring Extraction (SE), Heat reflux extraction (HRE), Ultrasound-assisted extraction (UAE), as well as the antioxidant capacity.

Conclusion. Microwave-assisted extraction showed obvious advantages in terms of high extraction efficiency and antioxidant activity of extract within shortest extraction time. Scanning electron microscopy (SEM) images of ginger powder materials after different extractions were obtained to provide visual evidence of the disruption effect. To our best knowledge, this is the first report about usage of MAE of 6-gingerol extraction from ginger, which could be referenced for the extraction of other active compounds from herbal plants.
\end{abstract}

Key words: microwave, 6-gingerol, polyphenols, antioxidant activity

\footnotetext{
*This work was supported by the '12th Five-Year Plan' National Key Technology R\&D programme of China (No. 2011 BAD23B01) and the Public Sector (Agriculture) Project Special Funds for Scientific Research (201303112). 


\section{INTRODUCTION}

Ginger (Zingiber offcinale Roscoe, Zingiberaceae) is widely used around the world in foods as spice and flavouring agent. It has a long history of medicinal use in China, Ayurvedic and Tibb-Unani against symptoms such as inflammation, rheumatic disorder, and gastrointestinal discomfort [Ali et al. 2008]. Gingerols have been identified as the major bioactive components in fresh ginger rhizomes, which exist as a homologous series of phenolic ketones with different chain lengths. Among various types of gingerols, 6-gingerol (Fig. 1) identified by Jolad et al. [2004] is one of the most pharmacologically active and abundant components [Kim et al. 2005]. The presence of $\alpha$-, $\beta$-hydroxy keto functional group in the structure of gingerols makes them susceptible to transformation to shogaol and zingerone at high temperature and long drying times [Bhattarai et al. 2001, Balladin et al. 1998, Jiang et al. 2007]. Based on previous reports, 6-gingerol has a wide array of biochemical and pharmacologic activities, including anti-oxidant, anti-inflammatory, analgesic, anti-mutagenic [Shukla et al. 2007], anti-angiogenesis [Kim et al. 2005], anti-emetic [Abdel-Aziz et al. 2006], anti-hyperglycemic [Chakraborty et al. 2012], and anticancer activities in vitro and in vivo [Lee et al. 2008, Nigam et al. 2009, Yang et al. 2010].

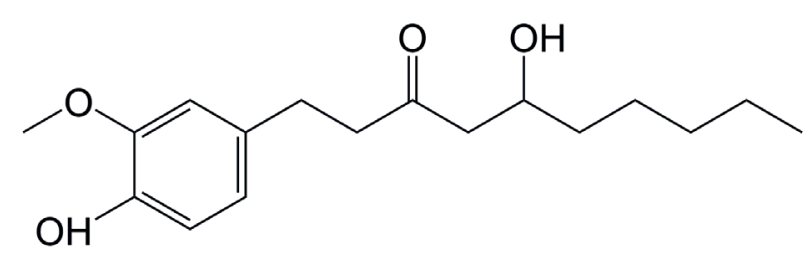

Fig. 1. Structure of 6-gingerol

In recent years, the application of microwave-assisted extraction (MAE) for obtaining bioactive compounds from plant materials has shown tremendous research interest and potential [Lee et al. 2008, Wu et al. 2012, Upadhyay et al. 2012]. MAE has higher extraction efficiency than conventional liquid-solid extraction techniques such as stirring extraction (SE), heat reflux extraction (HRE), ultrasonic-assisted extraction
(UAE) and maceration extraction (MAC) [Aspé and Fernández 2011, Mandal et al. 2010, Zhou and Liu 2006]. Studies showed that microwaves can penetrate plant matrix directly, resulting highly localized temperature and pressure inside plant cells, which can cause selective migration of target compounds into solvent rapidly [Yan et al. 2010, Upadhyay et al. 2012]. So far, microwave treatment has been widely employed to extract phenolics from different plant materials [Beejmohun et al. 2007, Kalia et al. 2008, Sutivisedsak et al. 2010, Tsubaki et al. 2010, Song et al. 2011]. To our best knowledge, usage of MAE has not been previously reported for 6-gingerol extraction in ginger.

In this study, microwave technique was employed to extract 6-gingerol from ginger. Response surface methodology was used to evaluate the effects of microwave power, extraction time, ethanol proportion and ratio of liquid to solid on the recovery of 6-gingerol to obtain the optimal extraction conditions. The extraction efficiency of MAE was compared with conventional extraction techniques. and antioxidant activity of different extractions were also investigated. The structural disruption to ginger with different extraction methods was observed by scanning electron microscopy (SEM).

\section{MATERIAL AND METHODS}

\section{Plant material and preparation}

Fresh ginger (Zingiber officinale Rosc.) purchased from a local supermarket (originally from Shandong, laiwu, China) was harvested at commercial maturity in September, 2013. It was washed clean, cut into slices and freeze-dried (Bulk tray dryer, Labconco, Kansas City, MO, USA). The dried ginger was ground into fine powder by a disintegrator (HX-200A, Yongkang Hardware and Medical Instrument Plant, China) and the materials which passed through a 60-mesh sieve were stored in air-tight plastic bags in the darkness at room temperature with in a day before following analysis.

\section{Chemical materials}

Folin-Ciocalteu reagent, 6-gingerol, 1,1-diphenyl-2-picrylhydrazyl (DPPH), acetonitrile of HPLC grade, 2,2'-azino-bis-(3-ethylbenzothiazoline-6-sulfonate) (ABTS) and Butylated hydroxytoluene (BHT) were 
purchased from Sigma Chemical Co. (St. Louis, MO, USA). Gallic acid was obtained from Sinopharm Chemical Reagent Peking Co. (Beijing, China). Ultrapure water was obtained in a Milli-Q waterpurification system (Millipore Corp., Bedford, MA, USA). Other used chemicals and reagents were of analytical grade.

\section{Analytical methods}

HPLC analysis of 6-gingerol was carried out on a YMC-Pack ODS-A $\mathrm{C}_{18}$ colum $(4.6 \times 150 \mathrm{~mm}$ i.d., $5 \mu \mathrm{m}$ particle size) using a Shimadzu HPLC (Tokyo, Japan) system equipped with a prominence UV-visible detector (SPD-20AV), a system controller (CBM-20A), an auto sampler (SIL-20A), two pumps (LC-20AT) and a column oven (CTO-20A). A well validated HPLC protocol for 6-gingerol developed by Cheng et al. [2011] was followed. Chromatographic separation was using $45 \mathrm{~min}$ linear gradient from $20 \%$ to $90 \%$ acetonitrile in water, followed by $90-100 \%$ acetonitrile over $5 \mathrm{~min}$, and then isocratic $100 \%$ acetonitrile for $10 \mathrm{~min}$. The column was re-equilibrated at the initial mobile phase composition for $10 \mathrm{~min}$. The flow rate was kept at $1 \mathrm{~mL} / \mathrm{min}$ and the detection wave-length was set at $280 \mathrm{~nm}$. Chromatogram was analysed on a Microsoft ${ }^{\mathrm{TM}}$ Windows $2000^{\mathrm{TM}}$ platform with DataApex Clarity ${ }^{\mathrm{TM}}$ software (Praha, Czech Republic). Qualitative and quantitative evaluation of 6-gingerol in the extract was performed on the basis of retention time and chromatographic behaviour with those of authentic standards. A five point calibration curve for 6-gingerol in the concentration range from $0.50 \mu \mathrm{g} / \mu \mathrm{L}$ to $1.5 \mu \mathrm{g} / \mu \mathrm{L}$ was constructed for the quantification of 6-gingerol content. The typical HPLC chromatogram of (a) 6-gingerol standard and (b) dynamic microwave-assisted extraction of 6-gingerol from ginger powder has been shown in Figure 2.
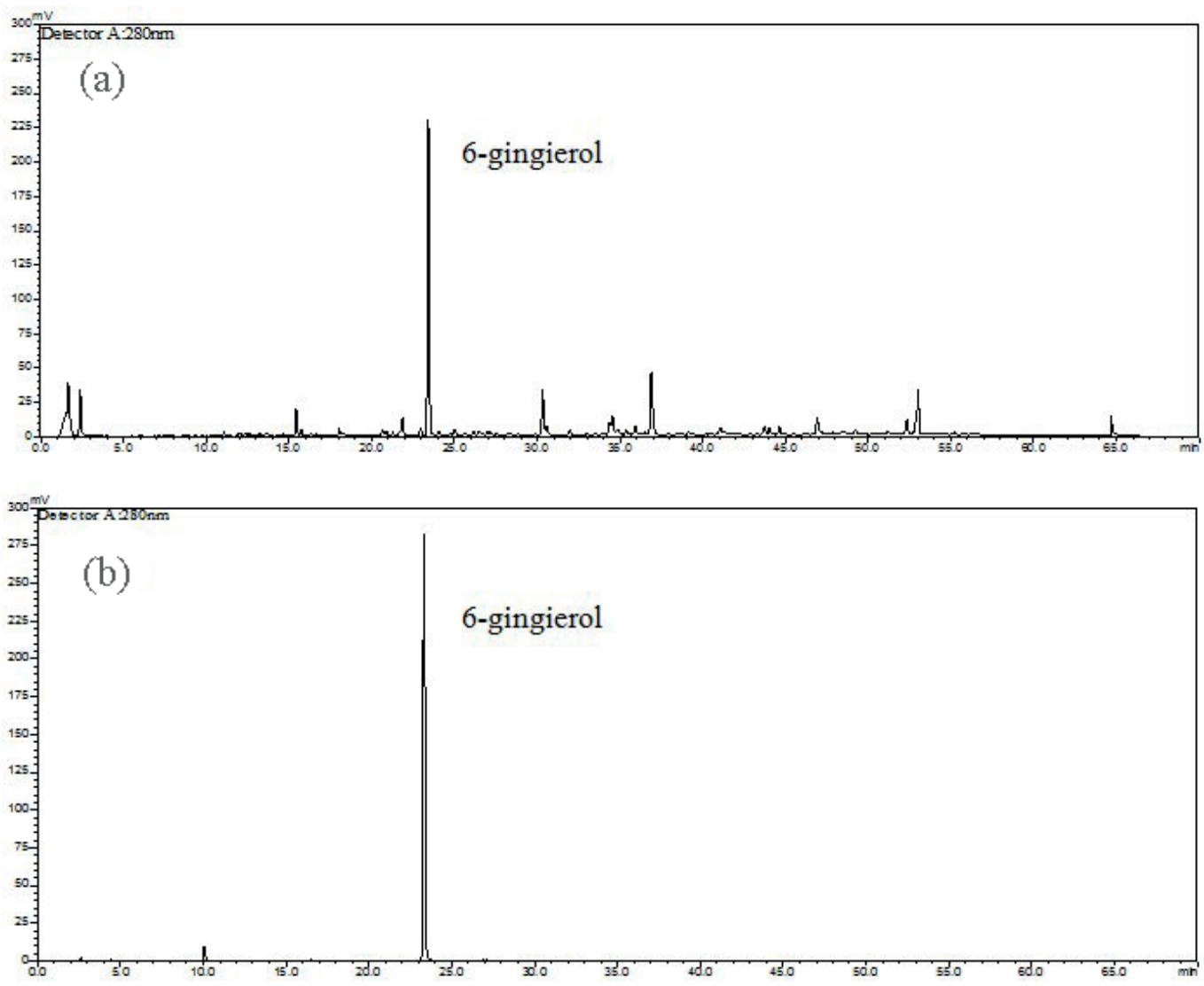

Fig. 2. HPLC chromatograms of standard 6-gingerol (a) and microwave-assisted extraction sample (b) 


\section{Experimental design}

RSM is a collection of statistical and mathematical techniques that has been successfully used to evaluate the effects of several process variables and their interactions [Liyana-Pathirana and Shahidi 2005]. In single-factor experiments for the recovery of 6-gingerol, proper ranges of ratio of liquid to solid (10:1, $\left.15: 1,20: 1,25: 1,30: 1,35: 1, \mathrm{~mL} \cdot \mathrm{g}^{-1}\right)$, ethanol proportion $(50,60,70,80,90,100 \% \mathrm{v} / \mathrm{v})$, microwave power
$(200,300,400,500,600,700 \mathrm{~W})$, extraction time (10, $20,30,40,50,60,70 \mathrm{~s})$ were determined. Based on the values obtained in single-factor experiments, a Box-Behnken design (BBD) was applied to determine the best combination of extraction variables, microwave power $\left(X_{1}, 400-600 \mathrm{~W}\right)$, ratio of liquid to solid $\left(X_{2}, 20\right.$ -30), extraction time $\left(X_{3}, 20-30 \mathrm{~s}\right)$ and ethanol proportion $\left(X_{4}, 70-90 \%\right)$ on the yield of 6-gingerol $(Y)$. Their actual and coded levels were presented in Table 1.

Table 1. Coded and real levels of operational parameters and observed responses

\begin{tabular}{|c|c|c|c|c|c|}
\hline Run & $X_{1}$ - power, $\mathrm{W}$ & $X_{2}-\mathrm{liq} / \mathrm{sol}$ & $X_{3}$ - time, $\mathrm{s}$ & $X_{4}$ - ethanol, \% & Yield of 6-gingerol, mg/g DW \\
\hline 1 & $0(500)$ & $0(25)$ & $0(30)$ & $0(80)$ & $15.35 \pm 0.722$ \\
\hline 2 & $0(500)$ & $1(30)$ & $0(30)$ & $-1(70)$ & $14.02 \pm 0.429$ \\
\hline 3 & $0(500)$ & $0(25)$ & $-1(20)$ & $1(90)$ & $12.85 \pm 0.691$ \\
\hline 4 & $0(500)$ & $-1(20)$ & $0(30)$ & $1(90)$ & $12.74 \pm 0.781$ \\
\hline 5 & $1(500)$ & $0(25)$ & $0(30)$ & $0(80)$ & $15.25 \pm 0.673$ \\
\hline 6 & $-1(400)$ & $1(30)$ & $0(30)$ & $0(80)$ & $12.94 \pm 0.489$ \\
\hline 7 & $-1(400)$ & $0(25)$ & $1(40)$ & $0(80)$ & $13.72 \pm 0.967$ \\
\hline 8 & $1(600)$ & $1(30)$ & $0(30)$ & $0(80)$ & $13.65 \pm 0.724$ \\
\hline 9 & $0(500)$ & $1(30)$ & $1(40)$ & $0(80)$ & $14.15 \pm 0.614$ \\
\hline 10 & $0(500)$ & $0(25)$ & $0(30)$ & $0(80)$ & $14.75 \pm 0.239$ \\
\hline 11 & $1(600)$ & $0(25)$ & $0(30)$ & $-1(70)$ & $13.98 \pm 0.539$ \\
\hline 12 & $0(500)$ & $1(30)$ & $0(30)$ & $1(90)$ & $13.28 \pm 0.365$ \\
\hline 13 & $0(500)$ & $0(25)$ & $-1(20)$ & $-1(70)$ & $13.25 \pm 0.425$ \\
\hline 14 & $0(500)$ & $1(30)$ & $-1(20)$ & $0(80)$ & $13.63 \pm 0.813$ \\
\hline 15 & $1(600)$ & $0(25)$ & $0(30)$ & $1(90)$ & $13.21 \pm 0.775$ \\
\hline 16 & $0(500)$ & $-1(20)$ & $-1(20)$ & $0(80)$ & $12.81 \pm 0.461$ \\
\hline 17 & $1(600)$ & $-1(20)$ & $0(30)$ & $0(80)$ & $14.35 \pm 0.549$ \\
\hline 18 & $1(600)$ & $0(25)$ & $-1(20)$ & $0(80)$ & $14.25 \pm 0.383$ \\
\hline 19 & $0(500)$ & $0(25)$ & $0(30)$ & $0(80)$ & $14.86 \pm 0.690$ \\
\hline 20 & $0(500)$ & $-1(20)$ & $0(30)$ & $-1(70)$ & $11.98 \pm 0.926$ \\
\hline 21 & $0(500)$ & $0(25)$ & $1(40)$ & $-1(70)$ & $14.12 \pm 0.965$ \\
\hline 22 & $-1(400)$ & $0(25)$ & $0(30)$ & $1(90)$ & $11.14 \pm 0.809$ \\
\hline 23 & $-1(400)$ & $0(25)$ & $0(30)$ & $-1(70)$ & $12.51 \pm 0.151$ \\
\hline 24 & $1(600)$ & $0(25)$ & $1(40)$ & $0(80)$ & $13.55 \pm 1.203$ \\
\hline 25 & $-1(400)$ & $-1(20)$ & $0(30)$ & $0(80)$ & $10.89 \pm 1.141$ \\
\hline 26 & $0(500)$ & $-1(20)$ & $1(40)$ & $0(80)$ & $12.96 \pm 1.212$ \\
\hline 27 & $-1(400)$ & $0(25)$ & $-1(20)$ & $0(80)$ & $11.34 \pm 0.948$ \\
\hline 28 & $0(500)$ & $0(25)$ & $1(40)$ & $1(90)$ & $13.41 \pm 0.453$ \\
\hline 29 & $0(500)$ & $0(25)$ & $0(30)$ & $0(80)$ & $15.45 \pm 0.916$ \\
\hline
\end{tabular}

DW - dry weight. 
The regression analysis was performed for the experiment data and fitted into the empirical second order polynomial model, as shown in the following equation:

$$
Y=\beta_{0}-\sum_{i=1}^{4} \beta_{j} X_{j}+\sum_{i=1}^{4} \beta_{i i} X_{i}^{2}-\sum_{i=1}^{3} \sum_{i j=i+1}^{4} \beta_{i j} X_{i} X_{j}
$$

where $Y$ represents the response variables, $\beta_{0}, \beta_{j}$, and $\beta_{i j}$ are the regression coefficients for intercept, linearity, square and interaction, respectively; $X_{i}$ and $X_{j}$ are the levels of the independent variables.

\section{Extraction procedures}

MAE was performed in a laboratory scale microwave extraction apparatus (MARS-II, $2450 \mathrm{MHz}$, Shanghai Sineo Microwave Products Company, Shanghai, China) at atmospheric pressure. The system supplies $1000 \mathrm{~W}$ of microwave energy at $100 \%$ power. Extraction of 6-gingerol was performed by adding $1.0 \mathrm{~g}$ of dried ginger powder into a certain ethanol solution at different parameters according to the experimental design.

Maceration (MAC) was carried out with $1.0 \mathrm{~g}$ dried ginger powder in $25 \mathrm{~mL}$ of $80 \%(\mathrm{v} / \mathrm{v})$ ethanol in a $100 \mathrm{~mL}$ closed conical flask at $25^{\circ} \mathrm{C}$ for $1 \mathrm{~h}$.

Stirring Extraction (SE) was carried out with $1.0 \mathrm{~g}$ dried ginger powder in $25 \mathrm{~mL}$ of $80 \%(\mathrm{v} / \mathrm{v})$ ethanol in a $100 \mathrm{~mL}$ closed conical flask by continuous stirring with the help of a magnetic stirrer at $25^{\circ} \mathrm{C}$ for $1 \mathrm{~h}$.

Heat reflux extraction (HRE) was carried out with $1.0 \mathrm{~g}$ dried ginger powder in $100 \mathrm{~mL}$ round-bottomed flask with $25 \mathrm{~mL}$ of $80 \%(\mathrm{v} / \mathrm{v})$ ethanol at $65^{\circ} \mathrm{C}$ for $60 \mathrm{~min}$.

Ultrasound-assisted extraction (UAE), a KQ-250DB ultrasonic bath (Kunshan Ultrasonic Instrument Co. Ltd., Jiangsu, China) with six transducers at the bottom was used as an ultrasound source. Extraction of 6-gingerol was executed with $1.0 \mathrm{~g}$ dried ginger powder in $25 \mathrm{~mL}$ of $80 \%$ (v/v) ethanol in a in a $100 \mathrm{~mL}$ closed conical flask placed in the ultrasonic bath set at $250 \mathrm{~W}$ in frequency of $40 \mathrm{kHz}$. Extraction was conducted for $60 \mathrm{~min}$ at the temperature of $65^{\circ} \mathrm{C}$.

For all the five methods, the extracts were centrifuged at room temperature for $10 \mathrm{~min}$ at $9000 \mathrm{~g}$ (Sigma 2-16P, Beijing Fine Best Trading Co. Ltd., China). The supernatant was collected, then diluted to the final volume of $25 \mathrm{~mL}$ with the extraction solvent, then passed through $0.45 \mu \mathrm{m}$ nylon filter and analysed for 6-gingerol content and total polyphenols content.

\section{Determination of total polyphenols content (TPC)}

The total polyphenols content was determined using Folin-Ciocalteu method [Singleton and Rossi. 1965] with a slight modification. $0.125 \mathrm{~mL}$ of Folin-Ciocalteu reagent and $0.5 \mathrm{~mL}$ of distilled water were mixed with $0.125 \mathrm{~mL}$ of the extract solution thoroughly. After standing for $10 \mathrm{~min}$ at room temperature, $1.25 \mathrm{~mL}$ of $(7.5 \% \mathrm{w} / \mathrm{v})$ sodium carbonate solution were added and the final volume was made up to $3 \mathrm{~mL}$ with distilled water, and the reaction mixture was incubated in dark for $90 \mathrm{~min}$ at $23^{\circ} \mathrm{C}$. The absorbance of solution was measured at $760 \mathrm{~nm}$ using on a UV-visible spectrophotometer (Shimadzu UV-1601 PC, Japan). A calibration curve was prepared, using a standard solution of gallic acid $(20,40,60,80$ and $100 \mathrm{mg} \cdot \mathrm{L}^{-1}, R^{2}=0.996$ ). Results were expressed as $\mathrm{mg}$ gallic acid $\cdot \mathrm{g}^{-1}$ dry ginger powder.

\section{DPPH radical scavenging assay}

The DPPH radical-scavenging assay was used to determine the antioxidant activity of extracts by different methods according to a previously established procedure [Hatano et al. 1988] with minor modifications. Extract solution $(0.1 \mathrm{~mL})$ in $95 \%$ methanol at various concentrations $(10,50,100 \mathrm{ppm})$ was mixed with 3.0 $\mathrm{mL}$ of methanolic solution of DPPH $[0.004 \%(\mathrm{w} / \mathrm{v})]$. The reaction mixture was incubated for $30 \mathrm{~min}$ in the darkness at room temperature. The absorbance of the resulting solution was measured at $517 \mathrm{~nm}$ with spectrophotometer. Methanol instead of sample solution was used as a control. BHT was assayed for comparison. DPPH scavenging capacity of the tested samples was measured as a decrease in the absorbance and was calculated using the following equation: scavenging activity $(\%)=\left[\left(A_{\text {control }}-A_{\text {test }}\right) / A_{\text {control }}\right] \times 100 \%$, where $A_{\text {control }}$ and $A_{\text {test }}$ are the absorbances at $517 \mathrm{~nm}$ of the control and test sample, respectively.

\section{$\mathrm{ABTS}^{*+}$ radical scavenging activity}

The antioxidant activities of different extractions in the reaction with stable $\mathrm{ABTS}^{++}$radical cation were performed according to the method of Re et al. [1999] with slight modification. Stock solution of ABTS $(2 \mathrm{mM})$ was prepared by dissolving in phosphate buffered saline (PBS, $50 \mathrm{~mL}$ ) and the $\mathrm{pH}$ of the solution should be 7.4. The ABTS radical cation $\left(\mathrm{ABTS}^{++}\right)$was produced by reacting ABTS stock solution $(7 \mathrm{mM})$ 
with $2.45 \mathrm{mM}$ potassium persulfate (final concentration) and allowing the mixture to stand in the dark at room temperature for 12-16 h before use. Prior to use in the assay, the $\mathrm{ABTS}^{++}$solution was diluted with PBS to obtain the absorbancyof $0.70 \pm 0.03$ at $734 \mathrm{~nm}$. Free radical scavenging activity was assessed by mixing $1.9 \mathrm{~mL}$ of diluted $\mathrm{ABTS}^{++}$solution with extract solution $(0.1 \mathrm{~mL})$ in $95 \%$ methanol at various concentrations $(10,50,100 \mathrm{ppm})$ and the absorbance was measured at $734 \mathrm{~nm}$, after $5 \mathrm{~min}$. PBS solution was used as a blank sample. BHT was assayed for comparison. $\mathrm{ABTS}^{++}$scavenging capacity of the tested samples was measured as a decrease in the absorbance and was calculated using the following equation: scavenging activity $(\%)=\left[\left(A_{\text {control }}-A_{\text {test }}\right) / A_{\text {control }}\right] \times 100 \%$, where $A_{\text {control }}$ and $A_{\text {test }}$ are the absorbances at $734 \mathrm{~nm}$ of the control and test sample, respectively.

\section{Scanning electron microscopy}

Samples before and after being treated by different extraction methods were scanned by Scanning electron microscopy (Quanta-200, FEI Company, USA). The materials were collected and air-dried after extraction. They were fixed on a specimen holder with an aluminum tape and sputtered with a thin layer of gold, and examined at an accelerating voltage of $15.0 \mathrm{kV}$ under high vacuum condition $(50 \mu \mathrm{m}, 2000 \times$ magnification $)$.

\section{Statistical analysis}

The extraction and analysis were performed in triplicate and the data were presented as mean \pm standard deviation (SD) values. Analysis of variance was performed by ANOVA procedure and Duncan's new multiple-range test was used to determine the differences of means using SAS (Version 8.1, 2000; SAS Inst., Cary, NC, USA). $P$ values $<0.05$ were regarded as significant and $P$ values $<0.01$ as very significant. RSM was performed using the Design Expert software (Version 7.1.3, Stat-Ease Inc., Minneapolis, MN).

\section{RESULTS AND DISCUSSION}

\section{Single factor experiments}

The effect of different ratio of liquid to solid on the extraction of 6-gingerol. To investigate the influence of liquid to material ratio on the yield of 6-gingerol, several loading ratios (10:1, 15:1, 20:1, 25:1, $\left.30: 1,35: 1, \mathrm{~mL} \cdot \mathrm{g}^{-1}\right)$ were examined, when the other three factors (microwave power, extraction time, and ethanol proportion) were fixed at $500 \mathrm{~W}, 30 \mathrm{~s}$, and $80 \%(\mathrm{v} / \mathrm{v})$. It can be seen in Figure 3 a that the yield of 6-gingerol was enhanced with the increase in the amount of solvent, before the ratio of solvent to material reached 25, at which the yield reached its highest value, and then it fell down slightly. This was probably because larger volume of solvent will cause more absorption of microwave energy, but sufficient microwave energy may not be available for breaking the cell walls for releasing of the target constituents [Hemwimon et al. 2007]. Similar effects were also recorded during the MAE of tea polyphenols and Ipomoea batatas leaves total phenolics [Pan et al. 2010, Song et al. 2011]. Therefore, $25 \mathrm{~mL} \cdot \mathrm{g}^{-1}$ was chosen as the ratio of liquid to solid through all the extraction optimization experiments.

The effect of different ethanol proportion on the extraction of 6-gingerol. Different ethanol proportion in ethanol-water mixtures was set at 50, 60, 70, 80, 90 and $100 \%(\mathrm{v} / \mathrm{v})$ to investigate the influence of ethanol proportion on the yield of 6-gingerol when the other reaction conditions were set as follows: microwave power $500 \mathrm{~W}$, extraction time $30 \mathrm{~s}$, ratio of liquid to solid $25 \mathrm{~mL} \cdot \mathrm{g}^{-1}$. Figure $3 \mathrm{~b}$ shows that the yield of 6-gingerol started to increase with increasing ethanol solutions concentrations, and reached a maximum at the ethanol solution concentration of $80 \%(\mathrm{v} / \mathrm{v})$, decreased with the increase of ethanol concentration. This was possibly due to that different ethanol concentrations have different polarities for high dielectric constant of water [Liu et al. 2013]. Therefore, the results may be related to the solvent polarity and the solubility of 6-gingerol in ginger, which was consistent with that ethanol solutions ranged from 40 to $80 \%$ had greater efficiency in the extraction of phenolics compared to pure ethanol [Hayouni et al. 2007, Song et al. 2011]. Therefore, $70-90 \%(\mathrm{v} / \mathrm{v})$ ethanol concentration in water was considered to be optimal in the following experiments.

The effect of different microwave power on the extraction of 6-gingerol. 6-Gingerol extraction process was carried out using different microwave power from $200 \mathrm{~W}$ to $700 \mathrm{~W}$, while other parameters were as follows: extraction time $30 \mathrm{~s}$, ethanol proportion $80 \%$, ratio of liquid to solid $25 \mathrm{~mL} \cdot \mathrm{g}^{-1}$, respectively. 

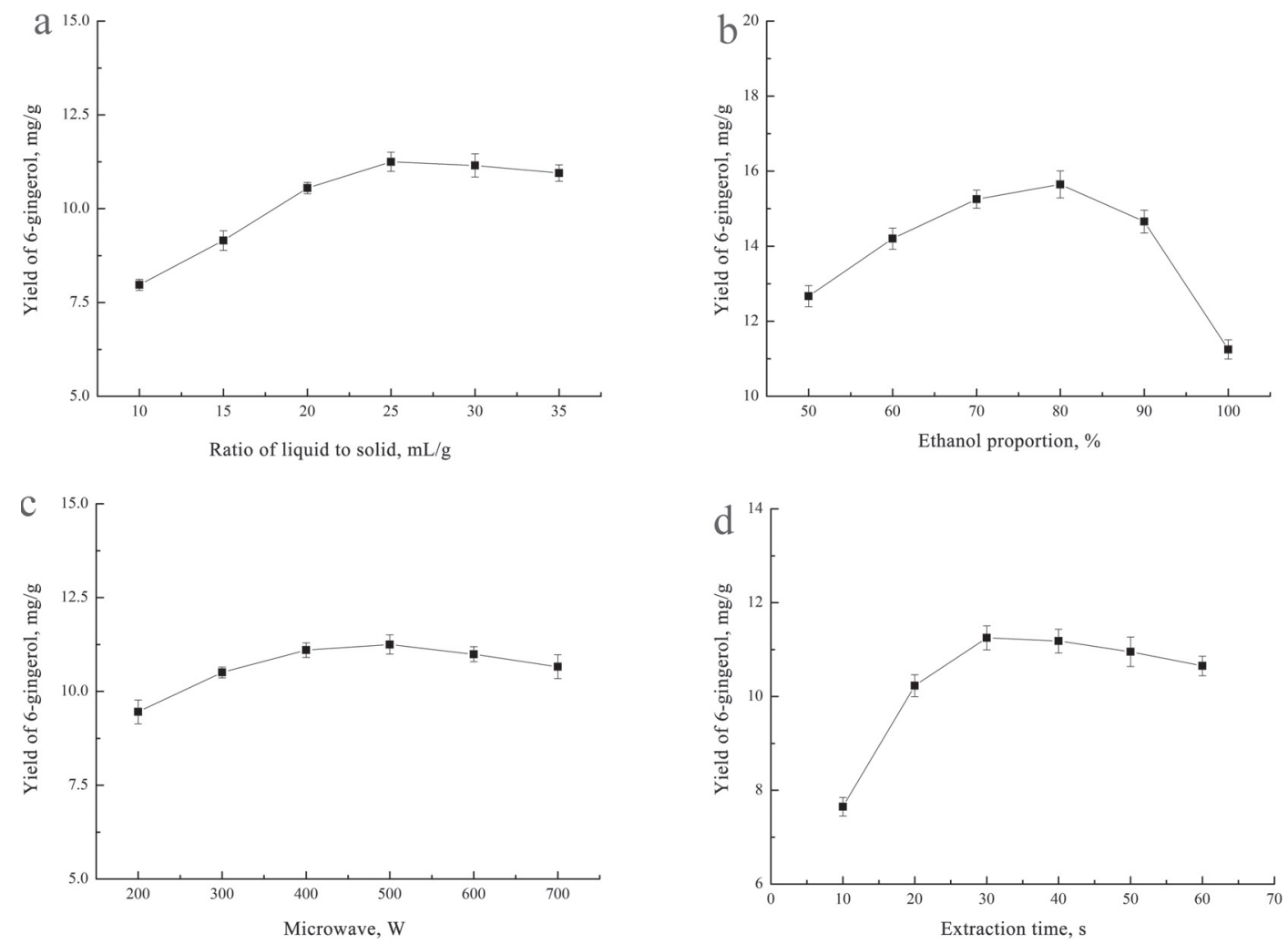

Fig. 3. Extraction yields of 6-gingerol from ginger powder during the evaluation of the following MAE parameters: $\mathrm{a}$ - ratio of solvent to solid, $\mathrm{ml} / \mathrm{g}$; $\mathrm{b}$ - ethanol proportion; $\mathrm{c}$ - microwave power, $\mathrm{W}$; $\mathrm{d}$ - extraction time, $\mathrm{s}$. Results were expressed as the mean value \pm standard deviation $(n=3)$

It was observed that there was significant improvement in extraction yield with an increase in microwave power between $200 \mathrm{~W}$ and $500 \mathrm{~W}$ (Fig. 3 c). When microwave power was higher than $500 \mathrm{~W}$, the extraction yield mildly decreased with the further increase of microwave power. These data suggest that applying a higher microwave power for a short time may be effective to extract 6-gingerol from ginger powder. However, a higher microwave power may cause the loss of 6-gingerol for degradation. Similar explanation was also reported to support the effect of microwave power on the MAE of chlorogenic acids from green coffee beans [Upadhyay et al. 2012] and MAE of gymnemic acid from Gymnema sylvestre [Mandal et al. 2009].

The effect of different extraction time on the extraction of 6-gingerol. The recovery of 6-gingerol affected by different extraction time $(10,20,30,40,50$,
60 and 70 s) was shown in Figure 3 d, when other three factors (microwave power, ethanol proportion and ratio of liquid to solid) were fixed at $500 \mathrm{~W}, 80 \%(\mathrm{v} / \mathrm{v})$ and $25 \mathrm{~mL} \cdot \mathrm{g}^{-1}$. The results indicated that the yield of 6-gingerol increased with the increase of extraction time from $10 \mathrm{~s}$ to $30 \mathrm{~s}$, and reached a peak at $30 \mathrm{~s}$, then slowly decreased. An adequate extraction time would make solubility of target compounds increase, but more prolonged treatment time might cause loss of active components. A similar result was also reported previously in MAE of flavonoid from Buddleia officinalis [Pan et al. 2010]. Herein the extraction time of 20-40 s was investigated in the present work.

\section{Optimization of MAE procedure}

Fitting the model. According to the values obtained in the single factor experiments and method of Box-Behnken designed experiment, RSM was applied 
Liu W., Zhou Ch.-Li, Zhao J., Chen D., Li Q.-H., 2014. Optimized microwave-assisted extraction of 6-gingerol from Zingiber officinale Roscoeand evaluation of antioxidant activity in vitro. Acta Sci. Pol., Technol. Aliment. 13(2), 155-168.

Table 2. Analysis of variance (ANOVA) for the experimental results

\begin{tabular}{lcrccc}
\hline \multicolumn{1}{c}{ Source } & Sum of squares & df & Mean square & $F$-value & $P$-value \\
\hline Model & 37.34 & 14 & 2.67 & 23.01 & $<0.0001$ significant \\
$X_{1}$ & 9.10 & 1 & 9.10 & 78.53 & $<0.0001$ \\
$X_{2}$ & 2.94 & 1 & 2.94 & 25.37 & 0.0002 \\
$X_{3}$ & 1.19 & 1 & 1.19 & 10.27 & 0.0064 \\
$X_{4}$ & 0.87 & 1 & 0.87 & 7.50 & 0.0160 \\
$X_{1} X_{2}$ & 1.89 & 1 & 1.89 & 16.31 & 0.0012 \\
$X_{1} X_{3}$ & 2.37 & 1 & 2.37 & 20.46 & 0.0005 \\
$X_{1} X_{4}$ & 0.090 & 1 & 0.090 & 0.78 & 0.3931 \\
$X_{2} X_{3}$ & 0.034 & 1 & 0.034 & 0.30 & 0.5954 \\
$X_{3} X_{4}$ & 0.56 & 1 & 0.56 & 0.21 & 0.6559 \\
$X_{1}^{2}$ & 9.95 & 1 & 9.95 & 85.85 & $<0.0001$ \\
$X_{2}^{2}$ & 6.55 & 1 & 6.55 & 56.50 & $<0.0001$ \\
$X_{3}^{2}$ & 2.95 & 1 & 0.95 & 25.48 & 0.0002 \\
$X_{4}^{2}$ & 8.11 & 1 & 8.11 & 70.02 & $<0.0001$ \\
Residual & 1.62 & 14 & 0.12 & & \\
Lack of fit & 1.24 & 10 & 0.12 & 1.30 & 0.4319 not significant \\
Pure error & 0.38 & 4 & 0.096 & & \\
Cor total & 38.96 & 28 & & & \\
$R^{2}$ & 0.9584 & & & & \\
C.V.\% & 2.53 & & & & \\
\hline
\end{tabular}

df - degrees of freedom.

to monitor the extraction characteristics of 6-gingerol in ginger powder and to determine the optimalconditions. The experiment design and experimental values of the responses were detailed in Table 1 . The analysis of variance (ANOVA) of 6-gingerol extraction yield revealed that the model was extremely significant $\left(P<0.0001\right.$; Table 2). The $R^{2}$ value for the model was 0.9584 with no significance in the lack of fit at $P>0.05$. These factors indicated that the model could work well for the prediction of the responses.

For the linear effects of each independent variable within the experimental range, it can be seen in Table 2 that 6-gingerol extraction yield was affected most significantly by microwave power $\left(X_{1} ; P<0.0001\right)$, followed by ratio of liquid to solid $\left(X_{2} ; P=0.0002\right)$, extraction time $\left(X_{3} ; P=0.0064\right)$ and ethanol proportion $\left(X_{4} ; P=0.0160\right)$. It was evident that all the linear and quadratic parameters and two interaction parameters $\left(X_{1} X_{2}, X_{1} X_{3}\right)$ were significant at the level of $P<0.05$ or $P<0.01$, whereas the other interaction parameters were insignificant $(P>0.1)$. Neglecting the non-significant parameters, the final predictive equation obtained:

$$
\begin{aligned}
Y= & 15.13+0.87 X_{1}+0.50 X_{2}+0.32 X_{3}-0.27 X_{4}- \\
& -0.69 X_{1} X_{2}-0.77 X_{1} X_{3}+0.15 X_{1} X_{4}+0.092 X_{2} X_{3}- \\
& -0.38 X_{2} X_{4}-0.077 X_{3} X_{4}-1.24 X_{1}^{2}-1.00 X_{2}^{2}- \\
& -0.67 X_{3}^{2}-1.12 X_{4}^{2}
\end{aligned}
$$

Response surface analysis. The effects of the independent variables and their mutual interaction on the extraction yield of 6-gingerol can also be seen on three-dimensional (3D) response surface curves and contour plots shown in Figure 4 a-f.

As shown in Figure 4 a, extraction yield increased rapidly when microwave power and ratio of liquid 


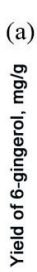
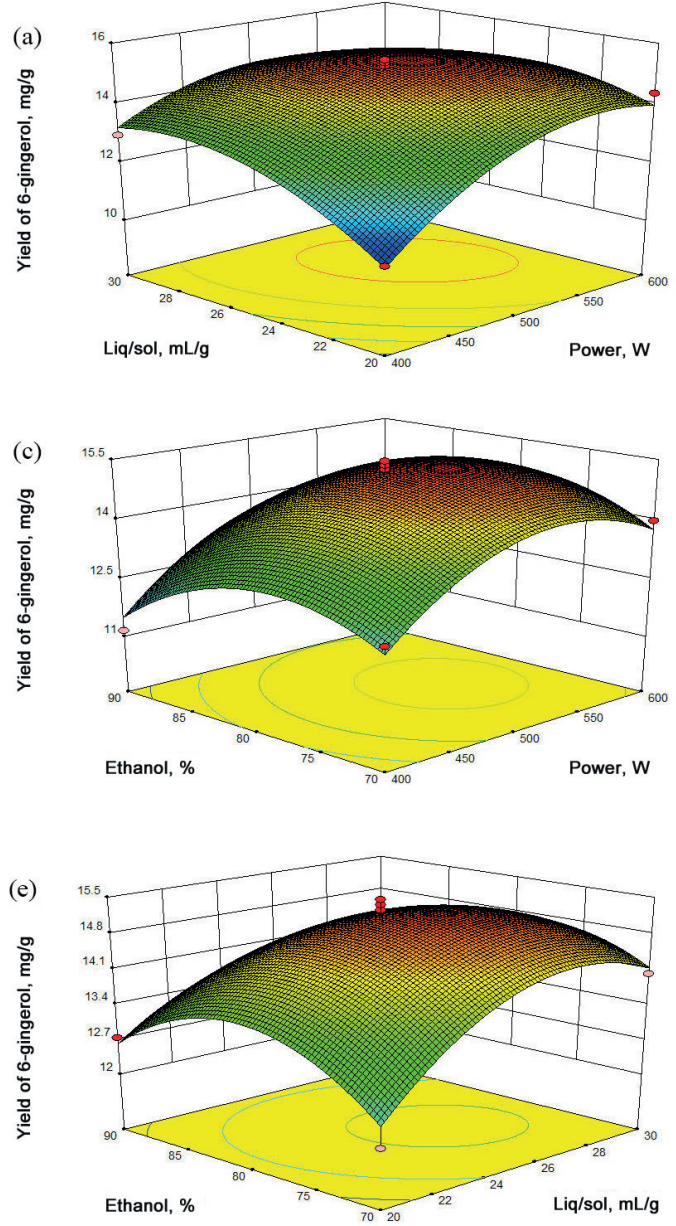
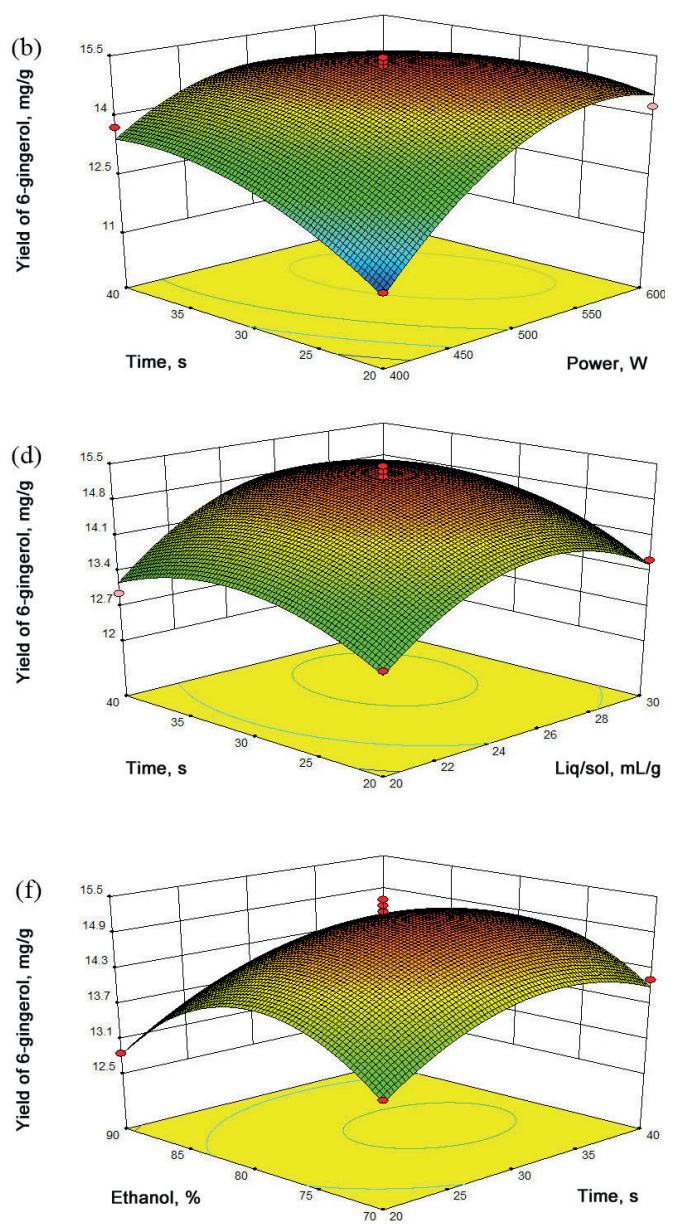

Fig. 4. Response surface (3D) showing the effect of different extraction parameters $\left(X_{1}\right.$ - microwave power, $\mathrm{W} ; X_{2}$ - ratio of liquid to solid, $\mathrm{mL} / \mathrm{g} ; X_{3}$ - extraction time, $\mathrm{s} ; X_{4}$ - ethanol proportion, \%) added on the response

to solid increased in the rage of 400-558 $\mathrm{W}$ and 20-27.83 $\mathrm{mL} \cdot \mathrm{g}^{-1}$, respectively; but beyond $558 \mathrm{~W}$ and $27.83 \mathrm{~mL} \cdot \mathrm{g}^{-1}$, extraction yield decreased slightly. This demonstrated that the effect of microwave power and ratio of liquid to solid on extraction yield was significant, which was in good agreement with the results in Table 2. Moreover, the mutual interactions between microwave power and liquid to solid ratio were also significant when the other variables were fixed at a constant.

From Figure $4 \mathrm{~b}$, microwave power and extraction time displayed a quadratic effect on extraction yield. Extraction yield increased at first and then decreased quickly with increasing of the two parameters, and a maximum extraction yield was achieved when microwave power and extraction time were $508 \mathrm{~W}$ and $37 \mathrm{~s}$, respectively. The mutual interaction between microwave power and extraction time were also significant.

Figure $4 \mathrm{c}$ showed the combined effect of microwave power and ethanol proportion on the extraction yield, and it revealed that at low and high levels of the ethanol concentration and ratio of liquid to solid the extraction yield was minimal. When ratio of liquid to solid was at certain value, the extraction yield increased with the increase of the ethanol proportion.

The combined effect of the liquid-solid ratio and extraction time was not significant, as can be seen 
in Figure $4 \mathrm{~d}$. The yield of 6-gingerol increased rapidly with the increase of extraction time at a fixed liquid to solid ratio, while with an increase in liquid to solid ratio beyond $26 \mathrm{~mL} \cdot \mathrm{g}^{-1}$, no obvious effect was observed on the extraction yield.

Figure 4 e showed that the solid-liquid ratio at $27 \mathrm{~mL} \cdot \mathrm{g}^{-1}$ and ethanol proportion at $77 \%$ gave the peak value of 6-gingerol content. It also can be observed that when varying ethanol proportion from $70 \%$ to $77 \%$ and liquid-solid ratio from 20 to 27 , the extraction of 6-gingerol was increasing when extraction time was at a certain value, while effect of ethanol proportion on the extraction yield was slighter. The same trend was observed for the interactive effect of extraction time and ethanol proportion on the yield of 6-gingerol in Figure $4 \mathrm{f}$.

Model validation. The reliability of the model equation for predicting the optimum response values was tested using the adjusted optimum conditions, which were concluded as follows: microwave power of $528 \mathrm{~W}$, ratio of liquid to solid of 26 , extraction time of $31 \mathrm{~s}$, ethanol proportion of $78 \%$, under which the experimental yield is $15.35 \pm 0.85 \mathrm{mg} \cdot \mathrm{g}^{-1}(n=3)$, agreeing closely with the predicted yield $15.33 \mathrm{mg} \cdot \mathrm{g}^{-1}$ and consequently confirming that the RSM model was adequate to reflect the expected optimization.

\section{Comparison of MAE traditional extraction methods}

6-gingerol content. The comparative analysis of extraction efficiency of 6-gingerol from ginger powder between MAE under optimum conditions and conventional extraction techniques was presented in Table 3 . MAC $\left(7.49 \pm 0.64 \mathrm{mg} \cdot \mathrm{g}^{-1}\right)$ and SE $\left(8.32 \pm 0.48 \mathrm{mg} \cdot \mathrm{g}^{-1}\right)$ had the lowest extraction efficiency compared with extraction methods, which are usually preferred for thermolabile constituents. HRE (12.71 $\left.\pm 0.92 \mathrm{mg} \cdot \mathrm{g}^{-1}\right)$ and UAE $\left(13.38 \pm 0.76 \mathrm{mg} \cdot \mathrm{g}^{-1}\right)$ had a similar extraction yield, which were worse compared with MAE. HRE is a time-consuming process, involves lengthy operation techniques and bulk amount of organic solvents, which may result in the degradation or conversion of the analytes [Zhang et al. 2008]. UAE mainly depends on the ultrasonic effects of acoustic cavitation. Since, the ultrasonic intensity distribution inside an ultrasonic bath is not homogeneous, which may induce the low precision of ultrasonic extraction [Flotron et al. 2003].

Table 3 indicated that compared with conventional extraction techniques, MAE is an excellent extraction method for 6-gingerol extraction with reduced extraction time, and solvent and energy consumption. Our results were in accordance with the findings of some other researchers [Proestos and Komaitis 2008, Xiao et al. 2008, Hayat et al. 2009, Pérez-Serradilla and Castro 2011] for the extraction of phenolic compounds from different plant materials by MAE.

Total polyphenols content and antioxidant capacities. The antioxidant capacities of extracts obtained by various methods at different concentration, ranging from 10 to $100 \mathrm{ppm}$ were evaluated by DPPH radical and $\mathrm{ABTS}^{-+}$radical assays (BHT as the positive control). Total polyphenols content was also measured in terms of gallic acid equivalents. From Table 4, the DPPH radical scavenging activity increased with increasing concentration of the extract in a dose dependent manner. The DPPH radical scavenging capability of all the tested samples is presented in the following descending order: $\mathrm{BHT}>\mathrm{MAE}>\mathrm{UAE}$

Table 3

\begin{tabular}{lccccc}
\hline $\begin{array}{c}\text { Extraction } \\
\text { method }\end{array}$ & Extraction time & $\begin{array}{c}\text { Ethanol } \\
\text { proportion, } \%\end{array}$ & Temperature, ${ }^{\circ} \mathrm{C}$ & $\begin{array}{c}\text { Ration of liquid } \\
\text { to solid, } \mathrm{mL} / \mathrm{g}\end{array}$ & Yield, mg/g \\
\hline MAE & $31 \mathrm{~s}$ & 78 & - & 26 & $15.35 \pm 0.85^{\mathrm{a}}$ \\
$\mathrm{MAC}$ & $1 \mathrm{~h}$ & 80 & 25 & 25 & $7.49 \pm 0.64^{\mathrm{b}}$ \\
$\mathrm{SE}$ & $1 \mathrm{~h}$ & 80 & 25 & 25 & $8.32 \pm 0.48^{\mathrm{c}}$ \\
$\mathrm{HRE}$ & $1 \mathrm{~h}$ & 80 & 65 & 25 & $12.71 \pm 0.92^{\mathrm{d}}$ \\
$\mathrm{UAE}$ & $1 \mathrm{~h}$ & 80 & 65 & 25 & $13.38 \pm 0.76^{\mathrm{e}}$ \\
\hline
\end{tabular}

Values are mean $\pm \mathrm{SD}, n=3$. Values followed by the same letter in the same row are not significantly different $(p<0.05)$. 
Liu W., Zhou Ch.-Li, Zhao J., Chen D., Li Q.-H., 2014. Optimized microwave-assisted extraction of 6-gingerol from Zingiber officinale Roscoeand evaluation of antioxidant activity in vitro. Acta Sci. Pol., Technol. Aliment. 13(2), 155-168.

Table 4

\begin{tabular}{lccccccc}
\hline \multirow{2}{*}{ Sample } & \multirow{2}{*}{ TPP, mg/g } & \multicolumn{2}{c}{ \% DPPH radical scavenging } & \multicolumn{2}{c}{ \% ABTS radical scavenging } \\
\cline { 3 - 8 } & & $10 \mathrm{ppm}$ & $50 \mathrm{ppm}$ & $100 \mathrm{ppm}$ & $10 \mathrm{ppm}$ & $50 \mathrm{ppm}$ & $100 \mathrm{ppm}$ \\
\hline MAC & $10.42 \pm 0.31^{\mathrm{a}}$ & $15.44 \pm 0.83^{\mathrm{a}}$ & $25.59 \pm 0.23^{\mathrm{a}}$ & $36.68 \pm 0.18^{\mathrm{a}}$ & $18.56 \pm 0.45^{\mathrm{a}}$ & $38.53 \pm 0.64^{\mathrm{a}}$ & $48.72 \pm 0.53^{\mathrm{a}}$ \\
$\mathrm{SE}$ & $12.64 \pm 0.73^{\mathrm{b}}$ & $17.38 \pm 0.75^{\mathrm{b}}$ & $30.75 \pm 0.46^{\mathrm{b}}$ & $41.79 \pm 0.46^{\mathrm{b}}$ & $20.26 \pm 0.33^{\mathrm{b}}$ & $41.41 \pm 0.72^{\mathrm{b}}$ & $52.14 \pm 0.49^{\mathrm{b}}$ \\
$\mathrm{HRE}$ & $20.41 \pm 0.56^{\mathrm{c}}$ & $25.61 \pm 0.42^{\mathrm{c}}$ & $45.14 \pm 0.82^{\mathrm{c}}$ & $65.13 \pm 0.72^{\mathrm{c}}$ & $27.89 \pm 0.43^{\mathrm{c}}$ & $50.07 \pm 0.61^{\mathrm{c}}$ & $71.48 \pm 0.34^{\mathrm{c}}$ \\
UAE & $22.45 \pm 0.49^{\mathrm{d}}$ & $26.87 \pm 0.78^{\mathrm{d}}$ & $50.39 \pm 0.63^{\mathrm{d}}$ & $72.66 \pm 0.46^{\mathrm{d}}$ & $28.79 \pm 0.68^{\mathrm{c}}$ & $54.62 \pm 0.48^{\mathrm{d}}$ & $77.63 \pm 0.19^{\mathrm{d}}$ \\
MAE & $24.65 \pm 0.63^{\mathrm{e}}$ & $27.94 \pm 0.25^{\mathrm{e}}$ & $55.53 \pm 0.49^{\mathrm{e}}$ & $78.83 \pm 0.35^{\mathrm{e}}$ & $30.83 \pm 0.42^{\mathrm{d}}$ & $61.75 \pm 0.34^{\mathrm{e}}$ & $84.71 \pm 0.79^{\mathrm{e}}$ \\
BHT & - & $29.85 \pm 0.37^{\mathrm{d}}$ & $60.29 \pm 0.53^{\mathrm{f}}$ & $82.37 \pm 0.86^{\mathrm{f}}$ & $32.46 \pm 0.18^{\mathrm{e}}$ & $65.32 \pm 0.59^{\mathrm{f}}$ & $88.92 \pm 0.84^{\mathrm{f}}$
\end{tabular}

Values are mean $\pm \mathrm{SD}, n=3$. Values followed by the same letter in the same row are not significantly different $(p<0.05)$.

$>\mathrm{HRE}>\mathrm{SE}>\mathrm{MAC}$. The same trend was also observed in $\mathrm{ABTS}^{++}$radical assay. The results suggested that MAE extract exhibited remarkable DPPH radical and $\mathrm{ABTS}^{++}$radical scavenging capabilities, which was stronger than traditional extraction methods at the same concentration. The high antioxidant activity of extracts of MAE can be explained owing to the presence of higher quantity of total polyphenols content, which confirms the usual correlation between antioxidant activity and total polyphenols content [Khan et al. 2010]. The results were also consistent with those reported in the literature, which have shown that applying MAE can increase the contents of antioxidants and reduce extraction time significantly as compared to conventional extraction methods [Hayat et al. 2009, Ballard et al. 2010].

\section{SEM observation}

In order to study the structural alteration during the different extraction techniques and to understand the extraction mechanism, the ginger samples were examined by SEM after the extraction. Figure 5 shows
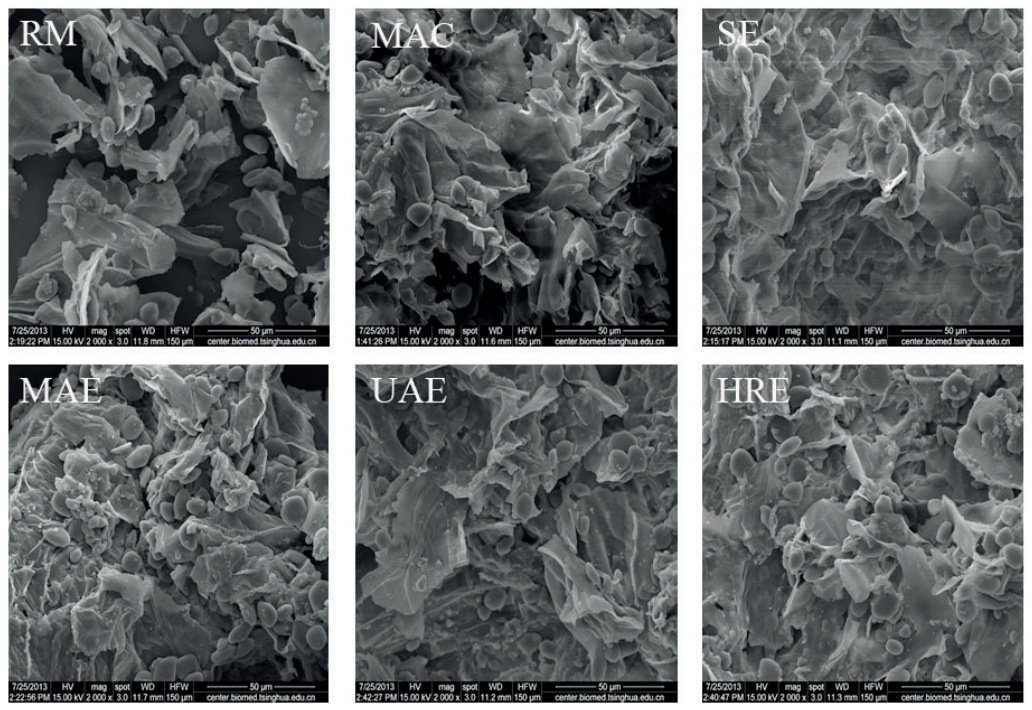

Fig. 5. SEM images $(50 \mu \mathrm{m}, 2000 \times$ magnification $)$ of ginger powder after MAC, SE, MAE, UAE, HRE 
the SEM micrographs of samples of raw materials (RM), MAC, SE, MAE, USE and HRE, respectively. In comparison with the control sample, extraction produced structural changes in all samples, although the extent of damage differed. In MAC and SE, the surfaces of the samples were not considerably different from those of the raw materials, only few slight creases and ruptures took place on the surfaces of the MAC and SE samples. Hence, the yields of 6-gingerol were the lowest among the different extraction techniques. In the process of HRE and UAE, no significant changes could be found for the surfaces of samples except for few creases and ruptures, which may be due to the long time heating or the via cavitation effects of ultrasound [Romdhane and Gourdon 2002]. However, the surface of the sample was greatly destroyed after MAE presented by profuse creases and ruptures. This observation suggests that the sudden thermal stresses and high localized pressures induced by microwave engery affect the structure of the cell, allowing easy entry of the solvent into cellular channels with high extraction efficiency [Mandal et al. 2008]. Other authors suggested this mechanism for the case of extracting astragalosides in Radix Astragali [Yan et al. 2010] and polyphenols from waste peanut shells [Zhang et al. 2013].

\section{CONCLUSIONS}

An optimized microwave-assisted extraction method of 6-gingerol from ginger has been developed. To the best of our knowledge, this is the first report on the combination usage of MAE for extraction and HPLCUV for quantification of 6-gingerol from ginger. The optimum MAE conditions were microwave power of $528 \mathrm{~W}$, ratio of liquid to solid of $26 \mathrm{~mL} \cdot \mathrm{g}^{-1}$, extraction time of $31 \mathrm{~s}$ and $78 \%$ ethanol proportion. The results showed that MAE has an obvious predominance for the extraction of 6-gignerol from ginger. Moreover, MAE was proven a more effective technique with less extraction time, higher total polyphenols content and greater antioxidant activities compared to conventional extraction techniques. The results in this study can be referenced for the extraction of other active compounds from herbal plants.

\section{REFERENCES}

Aspé E., Fernández K., 2011. The effect of different extraction techniques on extraction yield, total phenolic, and anti-radical capacity of capacity of extracts form Pinus radiata Bark. Ind. Crops Prod. 34 (1), 838-844.

Abdel-Aziz H.A., Windeck T., Ploch M., Verspohl E.J., 2006. Mode of action of gingerols and shogaols on 5- $\mathrm{HT}_{3}$ receptors: binding studies, cation uptake by the receptor channel and contraction of isolated guinea-pig ileum. Eur. J. Pharmacol. 530 (1-2), 136-143.

Ali B.H., Blunden G., Tanira M.O., Nemaar A., 2008. Some phytochemical, pharmacological and toxicological properties of ginger (Zingiber officinale Roscoe): a review of recent research. Food Chen Toxicol. 46 (2), 409-420.

Balladin D.A., Headley O., Yen I.C., McGaw D.R., 1998. High pressure liquid chromatographic analysis of the main pungent principles of solar dried West Indian ginger (Zingiber officinale Roscoe). Renew Energ. 13 (4), 531-536.

Ballard T.S., Mallikarjunan P., Zhou K., O’Keefe S., 2010. Microwave-assisted extraction of phenolic antioxidant compounds from peanut skins. Food Chem. 120 (4), 1185-1192.

Beejmohun V., Fliniaux O., Grand E., Lamblin F., Bensaddek L., Christen P., Kovensky J., Fliniaux M., Mesnard F., 2007. Microwave-assisted extraction of the main phenolic compounds in flaxseed. Phytochem. Anal. 18 (4), 275-282.

Bhattarai S., Tran V.H., Duke C.C., 2001. The stability of gingerol and shogaol in aqueous solutions. J. Pharm. Sci. 90 (10), 1658-1664.

Chakraborty D., Bishayee K., Ghosh S., Biswas R., Mandal S.K., Khuda-Bukhsh A.R., 2012. [6]-Gingerol induces caspase 3 dependent apoptosis and autophagy in cancer cells: drug-DNA interaction and expression of certain signal genes in HeLa cells. Eur. J. Pharmacol. 5 (694), 20-29.

Cheng X.L., Liu Q., Peng Y.B., Qi L., Li P., 2011. Steamed ginger (Zingiber officinale): Changed chemical profile and increased anticancer potential. Food Chem. 129 (4), 1785-1792.

Dewanto V., Wu X., Adom K.K., Liu R.H., 2002. Thermal processing enhances the nutritional value of tomatoes by increasing total antioxidant activity. J. Agric. Food Chem. 50 (10), 3010-3014.

Flotron V., Houessou J., Bosio A., Delteil C., Bermond A., Camel V., 2003. Rapid determination of polycyclic aromatic hydrocarbons in sewage sludges using 
microwave-assisted solvent extraction. J. Chromatogr. A, 999 (1-2), 175-184.

Hatano T., Kagawa H., Yasuhara T., Okuda T., 1988. Two new flavonoids and other constituents in licorice root: their relative astringency and radical scavenging effects. Chem. Pharm. Bull. 36 (6), 2090-2097.

Hayat K., Hussain S., Abbas S., Frooq U., Ding B., Xia S., Jia C., Zhang X., Xia W., 2009. Optimized microwaveassisted extraction of phenolic acids from citrus mandarin peels and evaluation of antioxidant activity in vitro. Sep. Purif. Technol. 70 (1), 63-70.

Hayouni E.A., Abedrabba M., Bouix M., Hamdi M., 2007. The effects of solvents and extraction method on the phenolic contents and biological activities in vitro of Tunisian Quercus coccifera L. and Juniperus phoenicea L. fruit extracts. Food Chem. 105 (3), 1126-1134.

Hemwimon S., Pavasant P., Shotipruk A., 2007. Microwaveassisted extraction of antioxidative anthraquinones from roots of Morinda citrifolia. Sep. Purif. Technol. 54 (1), 44-50.

Jiang H.L., Timmermann B.N., Gang D.R., 2007. Characterization and identification of diarylheptanoids in ginger (Zingiber officinale Rosc.) using high-performance liquid chromatography/electrospray ionization mass spectrometry. Rapid. Comm. Mass. Spectrom. 21 (4), 509-518.

Jolad S.D., Lantz R.C., Solyon A.M., Chen G.J., Bates R.B., Timmermann B.N., 2004. Fresh organically grown ginger (Zingiber offcinale): composition and effects on LPS-induced PGE 2 production. Phytochemistry 65 (13), 1937-1954.

Kalia K., Sharma K., Singh H., Singh B., 2008. Effects of extraction methods onphenolic contents and antioxidant activity in aerial parts of Potentilla atrosanguinea Lodd. and quantification of its phenolic constituents by RPHPLC. J. Agric. Food Chem. 56 (21), 10129-10134.

Khan M.K., Abert-Vian M., Fabiano-Tixier A., Dangles O., Chemat F., 2010. Ultrasound-assisted extraction of polyphenols (flavanone glycosides) from orange (Citrus sinensis L.) peel. Food Chem. 119 (2), 851-858.

Kim E., Min J., Kim T., Lee S., Yang H., Han S., Kim Y., Kwon Y., 2005. [6]-Gingerol, a pungent ingredient of ginger, inhibits angiogenesis in vitro and in vivo. Biochem. Bioph. Res. Co. 335 (2), 300-308.

Lee H.S., Seo E.Y., Kang N.E., Kim W.K., 2008. [6]-Gingerol inhibits metastasis of MDA-MB-231 human breast cancer cells. J. Nutr. Biochem. 19 (5), 313-319.

Li H., Deng Z., Wu T., Liu R., Loewen S., Tsao R., 2012. Microwave-assisted extraction of phenolics with maximal antioxidant activities in tomatoes. Food Chem. 130 (4), 928-936.

Liu Y., Wei S., Liao M., 2013. Optimization of ultrasonic extraction of phenolic compounds from Euryale ferox seed shells using response rurface methodology. Ind. Crops Prod. 49, 837-843.

Liyana-Pathirana C., Shahidi F., 2005. Optimization of extraction of phenolic compounds from wheat using response surface methodology. Food Chem. 93 (1), 47-56.

Mandal V., Dewanjee S., Mandal S.C., 2009. Microwaveassisted extraction of total bioactive saponin fraction from Gymnema sylvestre with reference to gymnemagenin: a potential biomarker. Phytochem. Anal. 20 (6), 491-497.

Mandal V., Mohan Y., Hemalatha S., 2008. Microwave assisted extraction of curcumin by sample-solvent dual heating mechanism using Taguchi L9 orthogonal design. J. Pharm. Biomed. Anal. 46 (2),322-327.

Nigam N., Bhui K., Prasad S., George J., Shukla Y., 2009. [6]-Gingerol induces reactive oxygen species regulated mitochondrial cell death pathway in human epidermoid carcinoma A431 cells. Chem. Biol. Interact. 181 (1), 77-84.

Pérez-Serradilla J.A., Castro M.D., 2011. Microwave-assisted extraction of phenolic compounds from wine lees and spray-drying of the extract. Food Chem. 124 (4), 1652-1659.

Pan Y., He C., Wang H., Ji X., Wang K., Liu P., 2010. Antioxidant activity of microwave-assisted extract of Buddleia officinalis and its major active component. Food Chem. 121 (2), 497-502.

Proestos C., Komaitis M., 2008. Application of microwaveassisted extraction to the fast extraction of plant phenolic compounds. Int. J. Food Sci. Tech. 41 (4), 652-659.

Re R., Pellegrini N., Proteggente A., Pannala A., Yang M., Rice-Evans C., 1999. Antioxidant activity applying an improved ABTS radical cation decolorization assay. Free Radical Biol. Med. 26 (9-10), 1231-1237.

Romdhane M., Gourdon C., 2002. Investigation in solid-liquid extraction: influence of ultrasound. Chem. Eng. J. 87 (1), 11-19.

Shukla Y., Prasad S., Tripathi C., Singh M., George J., Kualra N., 2007. In vitro and in vivo modulation of testosterone mediated alterations in apoptosis related proteins by [6]-gingerol. Mol. Nutr. Food Res. 51 (12), 1492-1502.

Singleton V.L., Rossi J.A., 1965. Colorimetry of total phenolics with phosphomolybdic-phosphotungstic acid reagents. Am. J. Enol. Viticult. 16 (3), 144-158.

Song J., Li D., Liu C., Zhang Y., 2011. Optimized microwave-assisted extraction of total phenolics (TP) from 
Ipomoea batatas leaves and its antioxidant activity. Innov. Food Sci. Emerg. 12 (3), 282-287.

Sutivisedsak N., Cheng H., Willett J.L., Lesch W.C., Tangsrud R.R., Biswas A., 2010. Microwave-assisted extraction of phenolics from bean (Phaseolus vulgaris L.) Food Res. Int. 43 (2), 516-519.

Tsubaki S., Sakamoto M., Azuma J., 2010. Microwave-assisted extraction of phenolic compounds from tea residues under autohydrolytic conditions. Food Chem. 123 (4), 1255-1258.

Upadhyay R., Ramalakshmi K., Rao L.M., 2012. Microwave-assisted extraction of chlorogenic acids from green coffee beans. Food Chem. 130 (1), 184-188.

Wu T., Yan J., Liu R., Marcone M.F., Aisa H.A., Tsao R., 2012. Optimization of microwave-assisted extraction of phenolics from potato and its downstream waste using orthogonal array design. Food Chem. 133 (4), 1292-1298

Xiao W., Han L., Shi B., 2008. Microwave-assisted extraction of flavonoids from Radix Astragali. Sep. Sci. Technol. 62 (3), 614-618.
Pan X., Niu G., Liu H., 2003. Microwave-assisted extraction of tea polyphenols and tea caffeine from green tea leaves. Chem. Eng. Process. 42 (2), 129-133.

Yan M., Liu W., Fu Y., Zu Y., Chen C., Luo M., 2010. Optimisation of the microwave-assisted extraction process for four main astragalosides in Radix Astragali. Food Chem. 119 (4), 1663-1670.

Yang G., Zhong L., Jiang L., Geng C., Cao J., Sun X., Ma Y., 2010. Genotoxic effect of 6-gingerol on human hepatoma G2 cells. Chem.-Biol. Interact. 185 (1), 12-17.

Zhang B., Yang R., Liu C.Z., 2008. Microwave-assisted extraction of chlorogenic acid from flower buds of Lonicera japonica Thunb. Sep. Sci. Technol. 62 (2), 480-483.

Zhang G., Hu M., He L., Fu P., Wang L., Zhou J., 2013. Optimization of microwave-assisted enzymatic extraction of polyphenols from waste peanut shells and evaluation of its antioxidant and antibacterial activities in vitro. Food Bioprod. Process 91 (2), 158-168.

Zhou H., Liu C., 2006. Microwave-assisted extraction of solanesol from tobacco leaves. J. Chromatogr. A, 1129 (1), 135-139.

For citation - Do cytowania

Liu W., Zhou Ch.-Li, Zhao J., Chen D., Li Q.-H., 2014. Optimized microwave-assisted extraction of 6-gingerol from Zingiber officinale Roscoeand evaluation of antioxidant activity in vitro. Acta Sci. Pol., Technol. Aliment. 13(2), 155-168. 